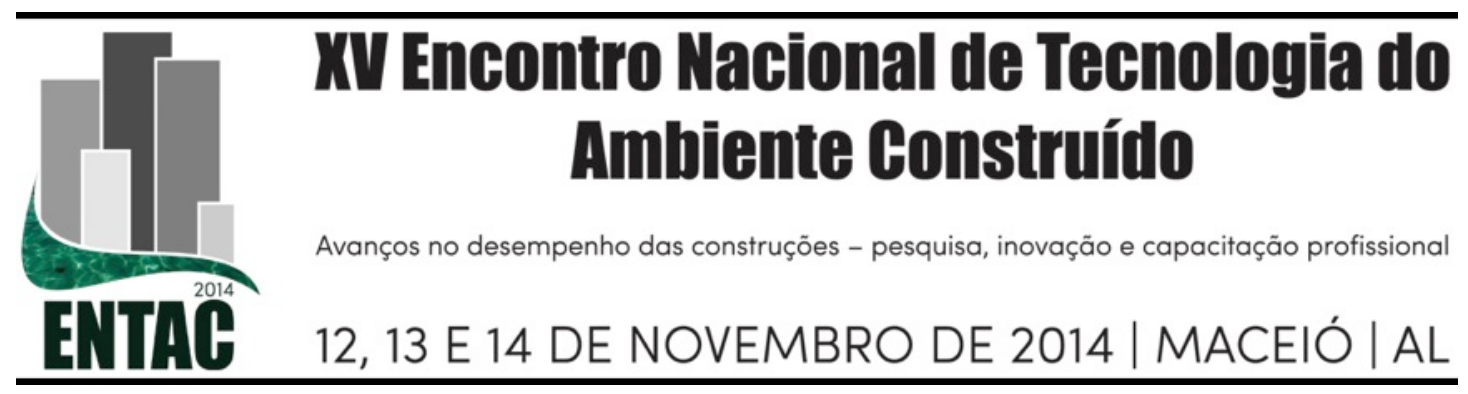

\title{
REFORÇO COM FIBRA DE CARBONO EM ALVENARIA ESTRUTURAL DE BLOCOS CERÂMICOS ANTIGOS
}

\author{
HÜTNER JÚNIOR, Ormy (1); GARCIA, Luiz Carlos (2); NÉIA, José Augusto (3) \\ (1) Universidade Federal do Paraná, 41 9977-9370, e-mail: junior@tellus.arq.br, (2) Instituto IDD, \\ cdominguez88@gmail.com, (3) Instituto IDD,jneia65@gmail.com
}

\begin{abstract}
RESUMO
Este trabalho verificou o aumento de resistência à compressão axial de um sistema construtivo de alvenaria estrutural composto por tijolos cerâmicos antigos, através da utilização de um sistema composto estruturado de fibra de carbono. Esta alternativa reparadora pode suprir as necessidades de reforços estruturais existentes nestes monumentos sem que haja grandes descaracterizações na sua concepção estrutural e estética original, procurando respeitar algumas premissas de salvaguarda do patrimônio material. Foram realizados ensaios de compressão axial em modelos reduzidos, que procuraram reproduzir as características originais das construções antigas. Nestes ensaios foram aplicados o sistema estruturado de fibra de carbono - CFC. O resultado destes ensaios demonstrou que a utilização de mantas de fibra de carbono em modelos reduzidos com argamassa cimentícia, aumentou a resistência à compressão destas estruturas em torno de 50\%. Assim, a aplicação do sistema composto estruturado de fibra de carbono em estruturas de alvenaria estrutural pode ser uma alternativa para intervenções em edifícios de valor histórico que apresentem manifestações patológicas devido ao comprometimento estrutural ao longo do tempo.
\end{abstract}

Palavras-chave: Restauro, Reforço Estrutural, Fibra de Carbono, Alvenaria.

\begin{abstract}
This work evaluated the increase of axial compressive strength of a structural masonry composed of old ceramic bricks, present in several buildings of historical value, by using a Carbon Fiber Reinforced Polymer (CFRP). Due to the precarious state of many buildings of patrimonial interest nowadays, this technics can supply the needs of structural reinforcements in these monuments without large modifications in its original structural and architectural design, respecting certain principles of preservation and safeguarding of society's material heritage. Tests were performed to determine the axial compressive strength on reduced models. For some models was applied the Carbon Fiber Reinforced Polymer (CFRP), placed in two different ways on the sidewalls of the samples. The final result of these tests demonstrated that the use of CFRP in models with composite mortar (cement, lime and sand) increased the axial compressive strength of these old constructive systems about 50\%. Thus, the application of CFRP on structural masonry structures can be an alternative in historical buildings' interventions with pathological manifestations due to lack of structural strength.
\end{abstract}

Keywords: Restoration, Structural Reinforcement, Carbon Fiber, Masonry.

\section{INTRODUÇÃO}

Este trabalho visa estudar os efeitos da aplicação de sistemas compostos com fibra de carbono em modelos reduzidos de alvenaria de tijolos cerâmicos antigos através de ensaios de resistência à compressão. Pode-se afirmar que atualmente a utilização de compostos estruturados de fibra de carbono para reforço estrutural do concreto armado tem-se difundido bastante entre os profissionais do ramo da engenharia de recuperação, 
oferecendo a estes uma nova e segura opção às demandas projetuais para serviços de recuperação e reforço estrutural [MACHADO, 2006]. A importação desta tecnologia para alvenarias se deve pela presença de várias manifestações patológicas presentes nestas estruturas.

O conhecimento hoje envolvendo a utilização de sistemas compostos estruturados com fibra de carbono (CFC) deve-se a pesquisas envolvendo sua utilização no reforço de estruturas de concreto armado. Contudo, novos estudos têm mostrado que com a utilização das fibras de carbono, muitas das causas de colapso em estruturas de alvenaria podem ser prevenidas ou reduzidas. Porém, ainda é necessário desenvolver mais estudos na área de recuperação e reforço de alvenarias com CFC [MACHADO, 2006].

Desta forma, este trabalho procura verificar a viabilidade técnica de utilização desta técnica, tão conhecida em estruturas de concreto armado, em edifícios históricos de alvenaria de tijolos cerâmicos antigos, como forma de recuperação e reforço estrutural, através de ensaios laboratoriais.

\section{OBJETIVO}

Avaliar se há ganho de resistência à compressão de uma parede de tijolos cerâmicos antigos após aplicação de sistema composto estruturado com fibra de carbono através de ensaios laboratoriais em modelos reduzidos.

\section{JUSTIFICATIVAS}

Segundo Castriota (2009) os antigos centros históricos transformaram-se em zonas excluídas dentro do próprio tecido urbano das cidades, fruto de uma sociedade industrial moderna que destruiu qualquer quadro de referências de usos, costumes e valores. Esta nova concepção de ocupação destruiu uma infinidade de "memórias individuais e coletivas" da sociedade, principalmente nos países em desenvolvimento, onde a expectativa e esperança contam mais que as reminiscências do passado.

Para o IPHAN (2004) a preservação é motivada pelo fato de nesses bens históricos serem reconhecidos um significado cultural, tornando-os dignos de medidas para ser tutelados para as próximas gerações, para que continuem a ser documentos fidedignos e efetivos suportes do conhecimento e da memória coletiva.

No âmbito da restauração, os princípios de intervenção em edifícios de valor histórico estão norteados pelas Cartas Patrimoniais. Estes documentos do ICOMOS (Conselho Internacional de Monumentos e Sítios), órgão vinculado à UNESCO (Organização das Nações Unidas para a Educação, Ciência e Cultura) são referências para projetos de restauro em todos os países consignatários da ONU (Organização das Nações Unidas) (KUHL, 2008).

Seguindo estes princípios, Kanan (2008) afirma que deve-se sempre buscar materiais que sejam compatíveis com os originais em projetos de conservação e restauração. $\mathrm{O}$ uso de materiais como o cimento Portland, em casos de conservação de estruturas construídas com sistemas tradicionais (sem a utilização deste material), tem apresentado problemas devido à incompatibilidade de propriedades que exibem essas argamassas em relação aos materiais antigos. Por este motivo, a utilização da fibra de carbono pode ser indicada para obras de restauração e conservação devido a sua característica, do ponto de vista estrutural, de não alterar as propriedades dinâmicas da estrutura, visto que estas permanecem inalteradas, pois não há acréscimo sensível de peso ou espessura (MACHADO, 2006). Assim, a adição do composto estruturado de fibra de carbono em edifícios de valor patrimonial interferiria pouco na natureza da edificação, ou seja, não 
afetaria a harmonia do conjunto arquitetônico, e resolveria problemas estruturais recorrentes de enfraquecimento estrutural do monumento fruto do desgaste natural ou imposto pela sua utilização inapropriada.

\section{MÉTODO DE PESQUISA}

Este trabalho estudou técnicas de recuperação que viabilizem o reforço de estruturas antigas sem comprometer sua autenticidade e adotando o preceito da reversibilidade (capacidade de recuperação do estado físico antes da intervenção aplicada) e mínima intervenção em restauração de bens imóveis.

Desta forma, primeiramente foram estudados e analisados os materiais e técnicas construtivas que envolvem a execução de alvenarias de blocos cerâmicos antigos autoportantes com argamassas aéreas e mistas, através de uma revisão bibliográfica dos materiais empregados neste trabalho.

Continuando esta revisão bibliográfica, foi realizado uma pesquisa referente a utilização de materiais a base de fibra de carbono para recuperação e reforço de estruturas. Em seguida, realizaram-se ensaios laboratoriais para verificar a resistência média à compressão dos prismas e das argamassas aéreas e mistas de assentamento. Os prismas foram submetidos a ensaios de compressão conforme NBR 8215 (ABNT, 1983) e as argamassas conforme NBR 13279 (ABNT, 2005).

Por se tratar de uma pesquisa experimental, que envolve procedimentos em laboratório, foram confeccionados modelos reduzidos de alvenaria de tijolos cerâmicos $(55 \times 55 \mathrm{~cm}) \mathrm{e}$ estes foram submetidos a ensaios de compressão axial.

Ressalta-se que estes modelos reduzidos foram executados com tijolos cerâmicos antigos, assentados com argamassa aérea e mista, conforme tipologias da época.

Após estes ensaios, foram apresentadas tabelas com os resultados obtidos nos ensaios de compressão dos prismas, argamassas e dos modelos reduzidos. Foram analisados os dados dos resultados dos ensaios das mini paredes (com aplicação ou não) pelo método de comparação, e assim foi possível dar um indicativo sobre a viabilidade técnica de utilização deste sistema de reforço estrutural em edificações de alvenaria estrutural de blocos cerâmicos antigos, em virtude do ganho ou não de resistência à compressão nos ensaios realizados em laboratório.

\section{PESQUISA EXPERIMENTAL}

\subsection{Ensaios de Corpos de Prova de Argamassa}

Durante a preparação para os ensaios com os modelos reduzidos de $55 \times 55 \mathrm{~cm}$, foram confeccionados doze corpos de prova para verificar a resistência à compressão da argamassa de assentamento. Estes estavam divididos em dois grupos - oito com argamassa aérea e quatro com argamassa mista, adotando os traços 1:4 (cal : areia média) e o traço 1:2:8 (cimento : cal : areia média), respectivamente.

O ensaio para obtenção da resistência à compressão da argamassa procurou atender a NBR 13279 (ABNT, 1995) - Argamassa para Assentamento e Revestimento de Paredes e Tetos - determinação da resistência à compressão e foi realizada em uma máquina universal de ensaios marca Emic, modelo DL 10.000, devidamente calibrada. Por razões técnicas não foi utilizada a norma atualizada para determinação da resistência à compressão de argamassa, a NBR 13279 (ABNT, 2005). 


\subsection{Ensaios de Prismas}

Simultaneamente à elaboração dos corpos de prova de argamassa, foram confeccionados seis prismas com quatro blocos cerâmicos antigos cada, utilizando em cinco prismas a argamassa aérea (cal : areia média, 1:4) e no sexto argamassa mista (cimento : cal : areia média 1:2:8). Quatro prismas foram rompidos com sete dias de cura e os outros dois com 40 dias de cura, de acordo com a NBR 8215 [ABNT, 1983]. Estes foram rompidos em um prensa servo-controlada, modelo DL 30.000 marca Emic, devidamente calibrada. Assim foi possível medir a resistência à compressão destes corpos de prova, pois este tipo de ensaio considera uma série de fatores como: a resistência à compressão dos blocos, a resistência à compressão das argamassas, a espessura da junta de assentamento e a qualidade da mão de obra. Os prismas foram assentados com argamassa com juntas de $01 \mathrm{~cm}$ de espessura aproximadamente.

\subsection{Ensaios de Modelos Reduzidos}

Foram produzidos dez modelos reduzidos ou "mini-paredes", de $55 \times 55 \mathrm{~cm}$, de tijolos de cerâmicos antigos (idade aproximada de 100 anos), que foram submetidos a um período de cura de 40 dias, divididos em dois grupos distintos. $\mathrm{O}$ primeiro grupo foi assentado com argamassa aérea (cal e areia, traço 1:4) e contou com quatro corpos de prova ao todo. O segundo grupo foi assentado com argamassa mista (cimento:cal:areia, traço 1:2:8) e continha seis modelos. A argamassa de assentamento foi aplicada com uma espessura de 1,0 cm nas fiadas das mini-paredes de alvenaria. Foi utilizada a cal hidratada para a produção da pasta de cal e esta foi "queimada" e reservada por sete dias para carbonatação até a sua utilização para produção da argamassa aérea e mista. Conforme modelo esquemático mostrado na figura 1, ambos os grupos foram submetidos a ensaios de resistência à compressão axial.

Figura 1 - Resumo Esquemático dos ensaios das mini-paredes
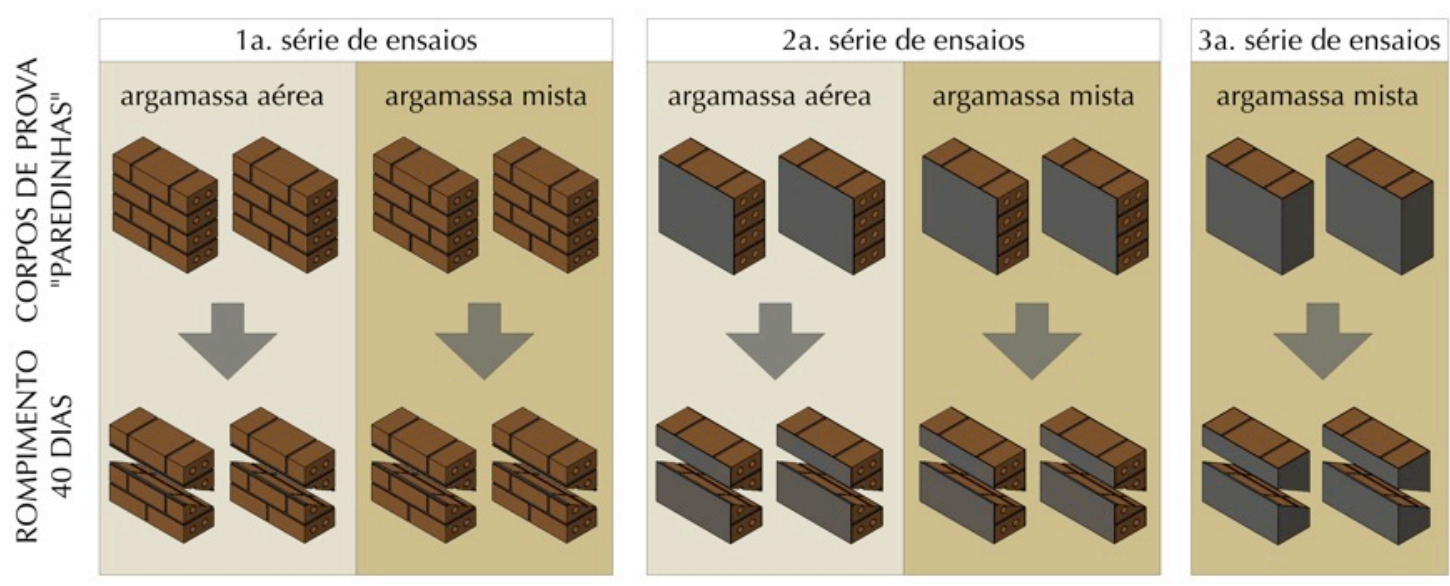

Fonte: Autores (2011)

Utilizou-se uma máquina universal de ensaios $30 \mathrm{~T}$, devidamente calibrada, conforme figura 2. Por não existir norma específica para a realização deste ensaio, utilizou-se a mesma velocidade de carregamento aplicada nos ensaios de determinação da resistência à compressão dos prismas. 


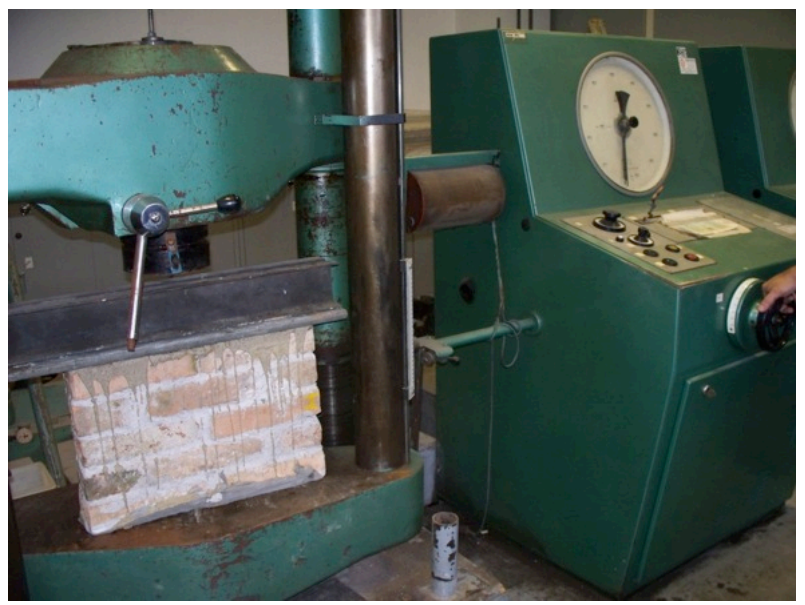

Fonte: Autores (2011)

$\mathrm{Na}$ primeira série de ensaios, os corpos de prova foram ensaiados sem qualquer aplicação de reforço com o sistema composto de fibras de carbono (CFC) com o propósito de se obter valores de referência das resistências dos modelos reduzidos. Nesta série foram utilizadas duas mini-paredes com argamassa aérea e outras duas argamassa mista, conforme figura 3. Assim, monitorou-se as tensões e deformações nos corpos de prova até seu rompimento.

\section{Figura 3 - Máquina Universal de ensaios Prensa 30T}

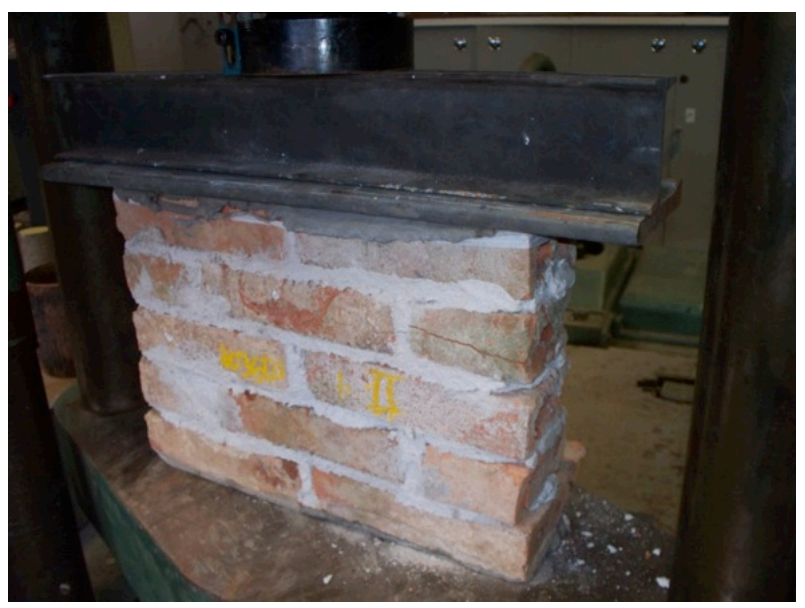

Fonte: Autores (2011)

A segunda série de ensaios com os modelos reduzidos foi realizada após aplicação do CFC sobre a argamassa de revestimento nas duas faces opostas das mini-paredes, sem que ocorra a possibilidade de ancoragem por envolvimento $(\Omega=0,75)$. Mais uma vez, rompeu-se dois modelos com argamassa aérea e outros dois com argamassa mista, conforme figura 4. Para aplicação das mantas de fibra de carbono se executou uma camada reguladora, além de uma base reguladora e um adesivo epoxídico. Todos os modelos foram completamente revestidos em um único sentido.

Figura $4-2^{\mathrm{a}}$ série de ensaios 


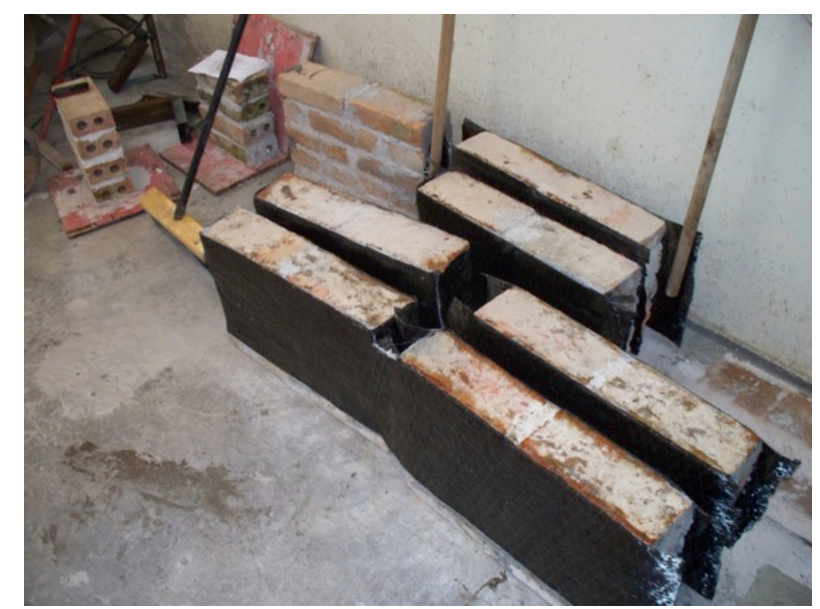

Fonte: Autores (2011)

A última série de ensaios com as "mini-paredes" foi realizada com apenas dois modelos assentados com argamassa mista, ao passo que desta vez o composto estruturado foi aplicado envolvendo completamente o painel $(\Omega=0,2)$, conforme figura 5 . As características de aplicação seguem as mesmas do ensaio anterior.

Figura $5-3^{a}$ série de ensaios

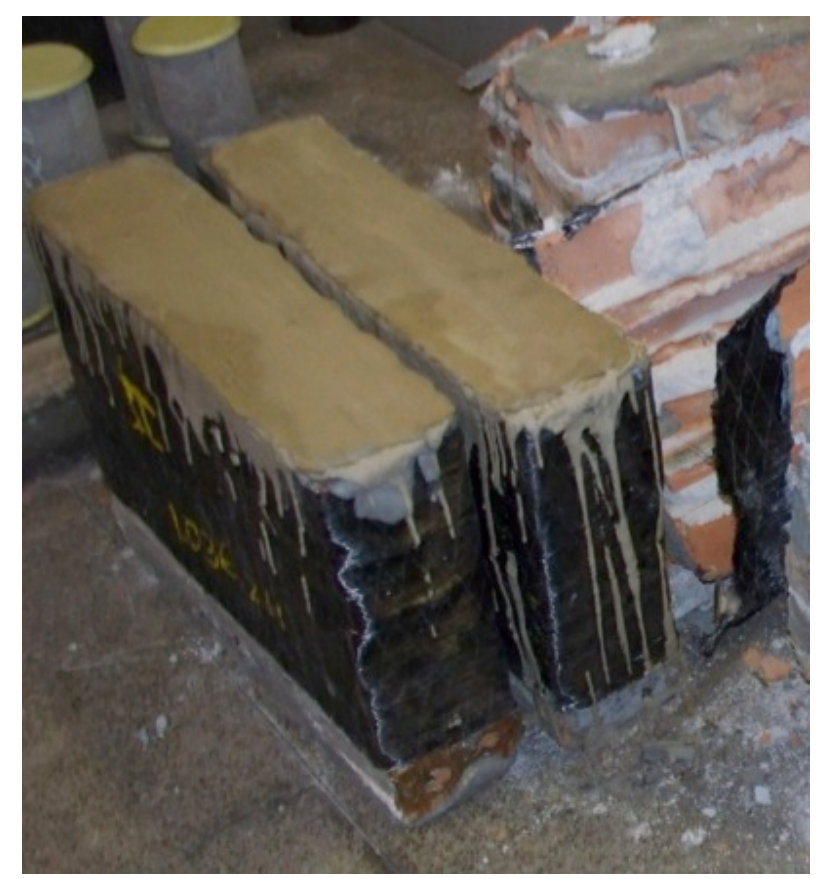

Fonte: Autores (2011)

\section{RESULTADOS}

Os resultados obtidos nestes ensaios podem ser vistos nos tópicos abaixo. 


\subsection{Resultado do ensaio de resistência à compressão axial das argamassas}

Este ensaio mostrou que os corpos de prova de argamassa mista são em média, aproximadamente 2,5 vezes mais resistentes à compressão que os mesmos com argamassa aérea. Ressalta-se mais uma vez que os resultados dos ensaios dos corpos de prova com 07 dias foram descartados e não constam na tabela 1.

Tabela 1 - Resistência à compressão axial das argamassas (NBR 13279, 1995)

\begin{tabular}{|c|c|c|c|c|}
\hline $\begin{array}{c}\text { Tipo de } \\
\text { Argamassa }\end{array}$ & Corpo de Prova & $\begin{array}{c}\text { Força Máxima } \\
\text { (N) }\end{array}$ & $\begin{array}{c}\text { Resistência à } \\
\text { compressão } \\
(\mathrm{MPa})\end{array}$ & $\begin{array}{l}\text { Idade } \\
\text { (dias) }\end{array}$ \\
\hline \multirow{5}{*}{$\begin{array}{l}\text { Argamassa } \\
\text { Aérea }\end{array}$} & 01 & 573 & 0,3 & \multirow{4}{*}{28} \\
\hline & 02 & 850 & 0,4 & \\
\hline & 03 & 836 & 0,4 & \\
\hline & 04 & 756 & 0,4 & \\
\hline & Média & 753,75 & 0,375 & \multirow{5}{*}{28} \\
\hline \multirow{5}{*}{$\begin{array}{l}\text { Argamassa } \\
\text { Mista }\end{array}$} & 01 & 2116 & 1,1 & \\
\hline & 02 & 1409 & 0,8 & \\
\hline & 03 & 1716 & 0,9 & \\
\hline & 04 & 1613 & 0,9 & \\
\hline & Média & 1713,5 & 0,925 & \\
\hline
\end{tabular}

Fonte: Autores (2011)

\subsection{Resultado do ensaio de resistência à compressão axial dos prismas}

Este ensaio demonstrou mais uma vez que os corpos de prova com argamassa mista são mais resistentes que os modelos com argamassa aérea, porém com uma diferença menor, em torno apenas de 50\%. Este ensaio mostra ainda a progressão de resistência da argamassa aérea, mostrando uma aumento de carga de quase $100 \%$ depois de 30 dias após a aferição de resistência com 07 dias, como se pode ver na tabela 2.

Tabela 2 - Resistência à compressão axial de prismas (NBR 8215, 1983)

\begin{tabular}{ccccc}
$\begin{array}{c}\text { Tipos de } \\
\text { Argamassa }\end{array}$ & Prisma & $\begin{array}{c}\text { Força Máxima } \\
(\mathbf{N})\end{array}$ & $\begin{array}{c}\text { Resistência em } \\
\text { MPa }\end{array}$ & $\begin{array}{c}\text { Idade } \\
\text { (dias) }\end{array}$ \\
\hline & 01 & $32.960,2$ & 1,1 & \\
\cline { 2 - 4 } & 02 & $33.479,9$ & 1,1 & 7 \\
\cline { 2 - 4 } $\begin{array}{c}\text { Argamassa } \\
\text { Aérea }\end{array}$ & 03 & $26.889,8$ & 0,9 & \\
\cline { 2 - 4 } & Média & $38.393,0$ & 1,2 & \\
\cline { 2 - 4 } & 05 & $\mathbf{3 2 . 9 3 0 , 7 2 5}$ & $\mathbf{1 , 0 7 5}$ & \\
\cline { 2 - 4 } & Média & $58.516,3$ & 1,9 & 40 \\
\cline { 2 - 4 } & 01 & $\mathbf{5 8 . 5 1 6 , 3}$ & $\mathbf{1 , 9}$ & \\
\hline Argamassa & $84.278,4$ & 2,7 & \\
\hline Mista & Média & $\mathbf{8 4 . 2 7 8 , 4}$ & $\mathbf{2 , 7}$ & \\
\hline & & & &
\end{tabular}

Fonte: Autores (2011)

\subsection{Resultado do ensaio de resistência à compressão axial dos prismas}

A tabela 3 descreve o comportamento dos modelos reduzidos nos ensaios de compressão axial, levando-se em conta o tipo de argamassa e o modo de aplicação da manta. Pode-se observar pelos resultados que as amostras que foram executadas com argamassa aérea, não apresentaram nenhum aumento de resistência com a aplicação do 
CFC. As tensões de ruptura foram basicamente as mesmas. Já nas amostras com argamassa mista, observou-se que houve um ganho em média de $50 \%$ de resistência quando submetidos à compressão, independente do modo como a manta foi aplicada (paralelamente ou por envolvimento completo).

Tabela 3 - resultado dos corpos de prova ensaiados à compressão axial

\begin{tabular}{|c|c|c|c|}
\hline $\begin{array}{l}\text { Condição de } \\
\text { reforço }\end{array}$ & Amostra & $\begin{array}{c}\text { Tensão de ruptura } \\
\text { (MPa) }\end{array}$ & $\begin{array}{c}\text { Força Máxima } \\
(\mathrm{N})\end{array}$ \\
\hline \multicolumn{4}{|c|}{ ARGAMASSA AÉREA } \\
\hline \multirow{3}{*}{$\begin{array}{l}\text { Sem reforço de } \\
\text { fibra de carbono }\end{array}$} & $\mathrm{P} 01$ & 1,1 & $66.685,2$ \\
\hline & P02 & 1,4 & $91.201,8$ \\
\hline & MÉDIA & 1,25 & $78.943,5$ \\
\hline \multirow{3}{*}{$\begin{array}{c}\text { CFC sem } \\
\text { ancoragem, } \\
\text { aplicação } \\
\text { paralela }(\Omega= \\
0,75)\end{array}$} & $\mathrm{P} 03$ & 0,9 & $58.839,9$ \\
\hline & P04 & 1,4 & $95.124,5$ \\
\hline & MÉDIA & 1,15 & $87.034,0$ \\
\hline \multicolumn{4}{|c|}{ ARGAMASSA MISTA } \\
\hline \multirow{3}{*}{$\begin{array}{l}\text { Sem reforço de } \\
\text { fibra de carbono }\end{array}$} & P05 & 2,0 & $130.428,4$ \\
\hline & P06 & 1,9 & $112.776,5$ \\
\hline & MÉDIA & 1,95 & $121.602,45$ \\
\hline \multirow{3}{*}{$\begin{array}{c}\text { CFC sem } \\
\text { ancoragem, } \\
\text { aplicação } \\
\text { paralela } \\
(\Omega=0,75)\end{array}$} & P07 & 2,8 & $180.442,4$ \\
\hline & P08 & 2,8 & $184.365,0$ \\
\hline & MÉDIA & 2,8 & $182.403,7$ \\
\hline \multirow{3}{*}{$\begin{array}{c}\text { CFC } \\
\text { envolvendo } \\
\text { completamente } \\
\text { o painel } \\
(\Omega=2,0)\end{array}$} & P09 & 2,8 & $185.345,7$ \\
\hline & $\mathrm{P} 10$ & 2,8 & $179.461,7$ \\
\hline & MÉDIA & 2,8 & $182.403,7$ \\
\hline
\end{tabular}

Fonte: Autores (2011)

\section{ANÁLISE DOS RESULTADOS}

Ao analisar os valores obtidos nas tabelas e gráficos acima, verificou-se que as argamassas que apresentam o cimento Portland como aglomerante junto à cal possuem capacidade de resistência 2,5 vezes maior que as argamassas aéreas, e assim como os prismas, que apresentaram uma resistência 50\% maior que os mesmos executados com argamassa aérea.

Em relação aos modelos reduzidos de $55 \times 55 \mathrm{~cm}$, constatou-se que a utilização de sistemas compostos de fibra de carbono em amostras com argamassa mista garantiu ao conjunto um aumento de resistência em torno de $50 \%$ em relação aos valores de referência (mini-paredes sem aplicação de manta de fibra de carbono), independente do 
tipo de ancoragem da mesma. Já o mesmo sistema mostrou-se ineficiente quando aplicado nas amostras com argamassa aérea, sem qualquer aumento de resistência.

\section{CONSIDERAÇÕES FINAIS}

Esta pesquisa mostrou que modelos reduzidos de alvenaria de blocos cerâmicos antigos, quando reforçados com sistemas compostos estruturados com fibra de carbono, apresentam ganho $50 \%$ de resistência quando submetidos à compressão axial. Porém os resultados obtidos não foram semelhantes quando se compara com o outro tipo de argamassa utilizada nos modelos. As amostras com argamassas aéreas não tiveram ganho algum de resistência à compressão neste trabalho como as amostras com argamassas mistas. Este efeito se deve em parte ao curto espaço de tempo de carbonatação da cal para produção da argamassa aérea. Assim, acredita-se que os modelos reduzidos com argamassas aéreas não representaram a veracidade com que estes sistemas construtivos se comportam hoje, sendo necessário em próximos estudos tentar reproduzir mais fielmente as características físicas, químicas e mecânicas destes elementos construtivos e desta maneira, refazer os ensaios de resistência à compressão. Contudo, esta técnica de reforço estrutural poderá vir a ser uma alternativa viável, tecnicamente, em construções de valor patrimonial, após novos ensaios e estudos a serem executados, já que este sistema interfere minimamente nos sistemas construtivos originais, preservando a dimensionalidade dos espaços originais, bem como os valores históricos que estão presentes em cada centímetro quadrado de cada parede, seja através de policromias parietais ou simplesmente a técnica construtiva antiga em si; pois este sistema de reforço estrutural mostrou-se inicialmente eficiente para recuperação estrutural de edifícios de valor patrimonial, desde que apresente argamassas mistas em seus elementos construtivos. 


\section{REFERÊNCIAS}

ASSOCIAÇÃO BRASILEIRA DE NORMAS TÉCNICAS. NBR 8215: Prismas de Blocos Vazados de Concreto Simples para Alvenaria Estrutural. Rio de Janeiro, 1983.

Rio de Janeiro, 1995.

NBR 13279: Argamassa para Assentamento - Resistência a Compressão.

.NBR 13279: Argamassa para Assentamento e Revestimento de Paredes e Tetos - determinação da resistência à compressão. Rio de Janeiro, 1995.

CASTRIOTA, Leonardo Barci. Patrimônio Cultural: conceitos, políticas, instrumentos. [São Paulo, SP]: Annablume, 2009, p. 82.

INSTITUTO DO PATRIMÔNIO HISTÓRICO E ARTÍSTICO NACIONAL. Cartas Patrimoniais. [Rio de Janeiro, RJ]: IPHAN, 2004, p. 92.

KANAN, Maria Isabel. Manual de Conservação e Intervenção em Argamassas e Revestimentos à Base de Cal. [Brasília, DF]: IPHAN/Programa Monumenta, 2008, p. 25.

KÜHL, Beatriz Mugayar. Preservação do Patrimônio Arquitetônico da Industrialização: problemas teóricos de restauro. [Cotia, SP]: Ateliê Editorial, 2008, p. 25.

MACHADO, Ari de Paula. Fibras de Carbono: Manual Prático de Dimensionamento. [Belo Horizonte, MG]: MBrace, 2006, p. 271. 